\title{
Need for recovery after work and the subsequent risk of cardiovascular disease in a working population
}

\author{
L G P M van Amelsvoort, IJ Kant, U Bültmann, G M H Swaen
}

Occup Environ Med 2003;60(Suppl I):i83-i87

See end of article for authors' affiliations

Correspondence to: Dr Ir LGPM van

Amelsvoort, Department of Epidemiology, Maastricht University, PO Box 616, 6200 MD Maastricht, Netherlands:

lgpm.vanamelsvoorł@ epid.unimaas.nl

Accepted

23 December 2002
Background: A high need for recovery after work can be regarded as a short term adverse effect of working day stressors and the person's inability to cope and recover. Consequently, it might be an intermediate factor between job stressors and cardiovascular disease (CVD).

Aim: To investigate, in a longitudinal study, the relation between need for recovery and subsequent CVD.

Methods: Data from the Maastricht Cohort Study of 12140 workers were used, with 42 incident self reported CVD cases during 32 months of follow up. Cox proportional hazards analysis was used to calculate age, gender, smoking status, and educational level adjusted relative risks.

Results: The adjusted relative CVD risk for the second compared to the first tertile of the need for recovery score was $1.22(95 \% \mathrm{Cl}: 0.49$ to 3.04$)$, and for the third compared to the first tertile was 3.16 (95\% Cl: 1.34 to 7.48$)$. When need for recovery was entered as continuous score, an adjusted relative risk per SD increase of $1.54(95 \% \mathrm{Cl}$ : 1.15 to 2.03$)$ was found. Additional adjustment for several work related factors as job demands, did not notably change the observed relation between need for recovery and CVD. Moreover, the increased risk for subjects reporting high job demands (1.38 per SD increase; $95 \% \mathrm{Cl}: 1.02$ to 3.92) decreased substantially after adjustment for need for recovery. Conclusion: The results show that need for recovery is a strong predictor of subsequent cardiovascular disease and might be an intermediate factor between job stressors and cardiovascular disease. in $\mathrm{n}$ recent decades a number of studies have been reported, investigating the relation between the psychosocial work environment and cardiovascular disease. Exposure to job stressors and its perception has been the main focus of most of these studies. The two most often used models in this field, the job strain model of Karasek and Theorell, ${ }^{1}$ and the high effort/low reward model by Siegrist ${ }^{2}$ have been of great importance for advances in this field of research. In a number of studies these models have been linked to cardiovascular morbidity and mortality. ${ }^{3-6}$ However, these models have not yet produced a comprehensive explanation of the increased cardiovascular morbidity and mortality, observed in a range of occupations. As stated in reviews by $\mathrm{Kasl}^{78}$ as well as by Kristensen," several methodological and more fundamental issues can be raised regarding the appropriateness of both models to quantify job stress. One of the methodological issues concerns whether the individual's perception rather than job average levels of job stressors are of greater importance. ${ }^{9}$ Another, more fundamental issue, is that as most people are exposed to many stressors, the perception and

\section{Main messages}

- A high need for recovery was found to be a risk factor for cardiovascular disease.

- Results indicated that need for recovery is an intermediate factor between job stressors and cardiovascular disease.

\section{Policy implications}

- Need for recovery is an interesting candidate for incorporation in future studies on the relation between job stressors and cardiovascular disease.

- Further research is needed to elucidate whether early intervention on respondents reporting a high need for recovery, for example by improving the work environment, is feasible and leads to a decreased cardiovascular disease morbidity and mortality. appraisal of the relative importance of the many simultaneous stressors by the concerned individual becomes impossible.'

More complex, and occupation specific measures have been proposed and might, in the future, yield more satisfactory results. ${ }^{10}$ However, another approach might be to focus on factors which potentially are indicators of the short term adverse effects of exposure to job stressors combined with a person's inability to cope with these stressors. Depue and Monroe ${ }^{11}$ suggested that the time required to recover from a stressor might be a good measure of the severity of the stress experienced because of this stressor, and can be a good predictor of the likelihood of long term chronic health effects. A potentially promising intermediate factor, in this respect, is "need for recovery". This concept has been related to adverse working conditions and insufficient unwinding after the exposure to workplace related stressors. ${ }^{12}{ }^{13}$ The results from the study by Sluiter and colleagues ${ }^{12}$ showed that "need for recovery" might be an intermediate factor in the relation between job stressors and mental health. ${ }^{12}$

No other studies have been found reporting on an increased need for recovery in relation to the occurrence of cardiovascular diseases. A concept, which is possibly marginally overlapping, is vital exhaustion. ${ }^{14}$ In several studies vital exhaustion has been linked with an increased cardiovascular disease risk. ${ }^{15}{ }^{16}$ Appels and Otten even hypothesised about the intermediate role of vital exhaustion between exposure to (job) stressors and cardiovascular disease. ${ }^{15}$ However, the concept of vital exhaustion is only marginally linked to workplace stress when compared to "need for recovery". Furthermore, vital exhaustion might be a consequence of a reduced cardiac output and could therefore also be regarded as a prodrome of cardiovascular disease (CVD) instead of a consequence of inverse working conditions.

Data from the Maastricht Cohort Study on fatigue at work enabled us to: (1) investigate whether in a healthy working

Abbreviations: CVD, cardiovascular disease; GHQ, General Health Questionnaire; JCQ, Job Content Questionnaire; RR, relative risk 
Table 1 Population characteristics, and crude, and also age, gender, educational level, and smoking status adjusted relative cardiovascular disease risk

\begin{tabular}{|c|c|c|c|}
\hline Variable & Mean (SD) or \% & $\begin{array}{l}\text { Crude relative risk } \\
(95 \% \mathrm{Cl})\end{array}$ & $\begin{array}{l}\text { Adjusted relative risk* } \\
(95 \% \mathrm{Cl})\end{array}$ \\
\hline Age & $41.6(8.5)$ & $2.59(1.72$ to 3.92$) \dagger$ & $2.19(1.42$ to 3.37$) \dagger$ \\
\hline Gender (male) & $72.5 \%$ & $\begin{array}{l}15.6 \\
(2.14 \text { to } 113.3) \ddagger\end{array}$ & $11.3(1.55$ to 83.0$) \ddagger$ \\
\hline \multicolumn{4}{|l|}{ Education } \\
\hline Low & $30.6 \%$ & 1 & 1 \\
\hline Intermediate & $31.9 \%$ & $0.60(0.29$ to 1.24$)$ & $0.81 \quad(0.39$ to 1.68$)$ \\
\hline High & $37.5 \%$ & $0.43(0.20$ to 0.92$)$ & $0.55(0.26$ to 1.2$)$ \\
\hline Smoking status (current smoker) & $24.4 \%$ & $2.84(1.55-5.19) \S$ & 2.74 (1.47 to 5.09$) \S$ \\
\hline Need for recovery & $0.37(0.26)$ & & \\
\hline Lowest tertile & & 1 & 1 \\
\hline Medium tertile & & $1.23(0.50$ to 3.02$)$ & 1.22 (0.49 to 3.04$)$ \\
\hline Highest tertile & & $3.56(1.43$ to 7.98$)$ & 3.16 (1.34 to 7.48$)$ \\
\hline Sleep quality score & $2.1(0.71)$ & & \\
\hline Poor sleep quality & $16.9 \%$ & $3.18(1.70$ to 5.95$)$ & 2.82 (1.48 to 5.35$)$ \\
\hline Psychological distress (GHQ) & $11.4(5.2)$ & & \\
\hline GHQ-case & $17.1 \%$ & 2.18 (1.14 to 4.20$)$ & 2.00 (1.02 to 3.92$)$ \\
\hline Night shift work & $24.1 \%$ & $1.42(0.74$ to 2.73$)$ & $1.34(0.63$ to 2.83$)$ \\
\hline Job demands (JCQ) & $33.1(5.64)$ & & \\
\hline Lowest tertile & & 1 & 1 \\
\hline Medium tertile & & 1.62 (0.67 to 3.90$)$ & $1.60(0.66$ to 3.86$)$ \\
\hline Highest tertile & & $2.48(1.10$ to 5.60$)$ & 2.29 (1.01 to 5.22$)$ \\
\hline Decision latitude (JCQ) & 72.3 (1 1.0) & & \\
\hline Highest tertile & & 1 & 1 \\
\hline Medium tertile & & 0.72 (0.33 to 1.57$)$ & 0.73 (0.33 to 1.62$)$ \\
\hline Lowest tertile & & 1.26 (0.63 to 2.52$)$ & $1.21 \quad(0.57$ to 2.56$)$ \\
\hline \multicolumn{4}{|c|}{$\begin{array}{l}\text { *Adjusted for age, gender, educational level, and smoking status. } \\
\text { †For age the relative risk is calculated per } 10 \text { years increase interval. } \\
\text { †Relative risk compared to females. } \\
\text { §Relative risk compared to current non-smokers. }\end{array}$} \\
\hline
\end{tabular}

population, increased levels of need for recovery are related to subsequent cardiovascular disease; and (2) to explore whether the relation is independent from job strain or potential confounders such as psychological distress.

\section{METHODS}

\section{Study population}

For the present study, data from the Maastricht Cohort Study on fatigue at work were used. This study has been described in detail elsewhere. ${ }^{17}$ In this prospective study, established in May 1998, 12140 workers, aged 18-65, employed by 45 different companies, mostly located in the southern part of the Netherlands are being followed. Written consent was obtained from all participants. All of the workers had a working contract of at least 16 hours per week; employees from temporary employment agencies were excluded because of anticipated follow up difficulties. For the current analysis all respondents with a history of cardiovascular disease at baseline were excluded from the analysis $(n=83)$. Workers without sufficient follow up data, that is, workers who did not respond on the four monthly follow up questionnaires during the first two years, were also excluded $(\mathrm{n}=4113)$. This left 7944 workers with a total of 20040 person-years of follow up (average follow up of 30.3 months). These data analyses are based on self reported cardiovascular diseases and after 32 months of follow up of the cohort, resulting in 42 incident cardiovascular disease cases.

\section{Need for recovery}

Need for recovery was assessed using a subscale of the VBBA (Dutch questionnaire on perception and judgement of work). ${ }^{131819}$ This 11-item questionnaire contains yes/no questions representing short term effects of a day of work, with questions like "I find it hard to relax at the end of a working day" and "When I get home, people should leave me alone for some time". An average score was calculated by adding the scores on the individual items, which were coded " 0 " or " 1 " in such a way that higher scores are related to "more complaints". The total score ranges from 0 to 1 (mean score 0.37 ; SD 0.26). For calculating relative risks, the score has been divided into tertiles. A more detailed description and correlates of "need for recovery" with fatigue and psychological distress has been described by Jansen and colleagues. ${ }^{13}$

\section{Cardiovascular disease}

At follow up questionnaires, two self reported indicators of incident cardiovascular disease (CVD) were combined into a single measure of self reported incident CVD. The items concerned a myocardial infarction or other serious heart condition and whether a medical doctor treated the respondent for this heart condition. Only cases treated by a medical doctor were included. The diagnosis in cases on sick leave for six weeks or more were confirmed by a structured telephone interview $(\mathrm{n}=35,83 \%)$.

\section{Demographic and health related factors}

Age, gender, educational level, and smoking status were queried at baseline. Psychological distress was assessed with a Dutch translation of the General Health Questionnaire (GHQ-12). ${ }^{20}{ }^{21}$ The Likert scores for the 12 items (0-3) were summed up to give a total GHQ score ranging from 0 to 36 . The traditional scoring method $(0,0,1,1)$ was used to identify individuals reporting substantial psychological distress to be classified as probable cases of minor psychiatric disorder (scoring 4 or more points in total). Sleep quality was assessed using one self formulated question: "Did you sleep well during the last four months", with the precoded answer categories "never", "sometimes", "mostly", and "always" coded from 1 to 4 .

\section{Work characteristics}

A good sleep quality was defined as scoring "mostly" or "always". Job strain, separated in psychological demands and decision latitude, was assessed using a validated Dutch version 


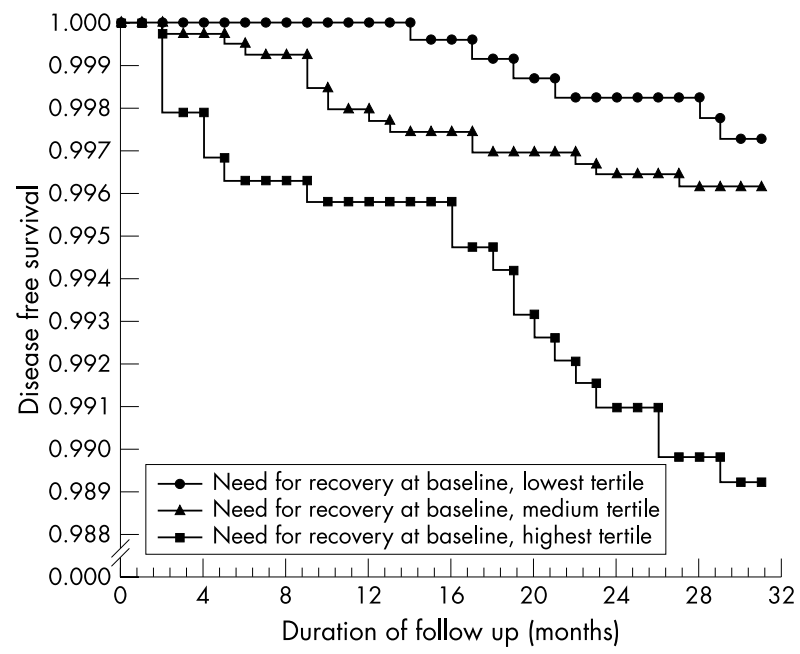

Figure 1 Cardiovascular disease free survival graph, according to need for recovery level tertile.

of the self administered Job Content Questionnaire (JCQ). ${ }^{22}{ }^{23}$ The shift work status was assessed by a detailed questionnaire regarding the working time. In this study shift work was defined as work, which includes working outside the normal working hours, including nights.

\section{Statistics}

For information, a correlation matrix between need for recovery and other factors is given in the appendix. Cox proportional hazards analysis was performed to calculate crude, and also age, gender, smoking status, and educational level adjusted relative risks using SAS. ${ }^{24}$

\section{RESULTS}

Table 1 presents the baseline characteristics, and crude, and also age, gender, educational level, and smoking status adjusted relative risks. For need for recovery, a significantly positive relation was found with the cardiovascular disease risk (adjusted RR: 3.16 for the highest versus the lowest tertile; $95 \%$ CI: 1.34 to 7.48). Exclusion of female workers did not change the relative risk considerably (adjusted RR: 3.15 for the highest versus the lowest tertile; 95\% CI: 1.33 to 7.47). A significant correlation was also observed for sleep quality and psychological distress. For the job strain variables, psychological job demands, and decision latitude, only job demands showed a significant correlation with the CVD risk.

From the CVD event-free survival curve for different levels of the "need for recovery" score, as presented in fig l, it can be observed that the difference in CVD risk for the highest "need for recovery" tertile is not restricted to the first year of follow up but remains constant throughout the entire 32 month follow up period. This is reflected in the relative risk, calculated with exclusion of the incident CVD cases during the first year of follow up (which leaves 25 incident cases for analysis). The continuous score adjusted relative risk decreased from 1.54 to 1.48 (95\% CI: 1.03 to 2.11 ) per SD increase, when excluding the incident CVD cases during the first year.

When investigating whether the increased risk found for need for recovery remains after simultaneous adjustment for the other measures included in this study, the problem of colinearity of the Cox proportional hazards model arises because of the correlation between the different measures (see correlation matrix in the appendix) along with the relatively low number of incident cardiovascular disease cases. A model adjusting for all measures simultaneously is therefore deemed to be unstable. In order to be able to tell whether the overlapping part or the difference between the measures is important,
Table 2 Age, gender, educational level, and smoking status adjusted cardiovascular disease risks: models with need for recovery and subsequently one other independent variable next to age, gender, educational level, and smoking status

\begin{tabular}{ll}
\hline Model & Relative risk $(95 \% \mathrm{Cl})^{*}$ \\
\hline Need for recovery & $1.54(1.15$ to 2.03$)$ \\
Sleep quality & $0.73(0.56$ to 0.96$)$ \\
Psychological distress (GHQ) & $2.15(1.30$ to 3.56$)$ \\
Job demands & $1.38(1.02$ to 3.92$)$ \\
Decision latitude & $0.92(0.67$ to 1.27$)$ \\
Working nights & $1.34(0.63$ to 2.83$)$ \\
Sleep quality & $0.82(0.61$ to 1.10$)$ \\
Need for recovery & $1.38(1.02$ to 1.88$)$ \\
& $1.59(0.86$ to 2.94$)$ \\
Psychological distress (GHQ-12) & $1.53(0.96$ to 2.43$)$ \\
Need for recovery & $1.19(0.86$ to 1.64$)$ \\
Job demands & $1.45(1.07$ to 1.96$)$ \\
Need for recovery & $1.02(0.74$ to 1.41$)$ \\
Decision latitude & $1.54(1.15$ to 2.05$)$ \\
Need for recovery & $1.27(0.60$ to 2.69$)$ \\
Working nights & $1.52(1.15$ to 2.02$)$ \\
\hline Need for recovery &
\end{tabular}

*The relative risk is calculated per standard deviation increase (except for working nights), adjusted for age, gender, educational level, and smoking status.

we opted to present age, gender, education level, and smoking status adjusted models including need for recovery and subsequently one of the other possible explanatory factors: sleep quality, psychological distress (GHQ), psychological job demands, the decision latitude score, and working at nights. Table 2 presents the results of these models. To enable evaluation of the changes in these relative risks due to the additional adjustment, the relative risks only adjusted for age, gender, education level, and smoking status are also presented in this table. For subsequent adjustment for the other explanatory factors, the relative risk for need for recovery showed only marginal changes.

Compared to sleep quality, job demands, and decision latitude scores, the "need for recovery" score was found to be the strongest predictor (highest relative risk per standard deviation increase in the score) of subsequent cardiovascular disease. The relative risk for psychological distress was found to be of a similar magnitude as need for recovery in relation to subsequent cardiovascular disease. Adjustment for the factors mentioned above did not greatly change the relative risk for need for recovery. The age, gender, educational level, and smoking status adjusted relative risk per standard deviation increase of need for recovery of 1.54 decreased maximally to 1.38 (when adjusted for sleep quality). A substantial decrease, from 1.38 to 1.19 per standard deviation was found for the relative risk for job demands, when adjusted for need for recovery.

\section{DISCUSSION}

In this study the need for recovery was found to be a predictor of subsequent cardiovascular disease in the next 32 months. Even with the very mild cut off points where $33 \%$ of the working population is "exposed" (tertile), the adjusted relative risk was found to be 3.16 ( 1.34 to 7.48 ). This risk only marginally decreased after exclusion of the cases occurring during the first year of follow up. Furthermore, adjustment for potential explanatory factors did not considerably influence the relation between need for recovery and subsequent cardiovascular disease. 
These findings, especially the stability over time, in our view give weight to the hypothesis that a high need for recovery is an intermediate factor between adverse working conditions and/or poor coping with these conditions and their long term cardiovascular effects compared to the hypothesis that an increased need for recovery is a consequence of underlying heart disease and thus related to cardiovascular disease. This intermediate role of "need for recovery" between work conditions and health outcomes is in accordance with results from a study of Sluiter and colleagues ${ }^{12}$ who found similar results for mental health outcomes.

The following issues, however, must be kept in mind when considering these results. Firstly, the CVD incident cases are based on self reported data. As we only consider respondents indicating that they have received treatment by a medical doctor for their heart condition, patients who died shortly after the onset of their cardiovascular problems could not be included in the analysis. This has probably resulted in exclusion of the most severe cases. Most likely, this would have caused a underestimation of the true effect of the relationships. Furthermore, as suggested by Macleod and colleagues, ${ }^{25}$ self reported CVD might lead to spurious associations between psychosocial measures and disease outcomes. However, as we asked for medically affirmed CVD, in our study we do not consider this an important source of bias. Secondly, the results are based on a relatively small number of incident CVD cases. This complicated a stratified analysis for gender, or other potential effect modifiers. Therefore, we are not able to tell whether there is a different effect for men and women, or whether there is interaction between, for example, job strain and need for recovery. However, the analysis restricted to male respondents revealed no considerable changes in the reported relative risks. As a third issue, our study was conducted among a working population, with most workers of age groups in which the CVD risk is relatively low. One might assume that the health effects of adverse working conditions will slowly fade after retirement. Therefore the strongest and best estimates between work and work related CVD should be found when the CVD follow up period is restricted to the working population during employment. This is an aspect ignored by most other studies conducted in this field so far, as they extended their follow up periods far beyond retirement in order to increase the number of cases. Fourthly, psychological distress may be an important confounder when investigating the relation between need for recovery and cardiovascular disease. Psychological distress has been reported as an independent risk factor for cardiovascular disease, ${ }^{26}$ and distressed people might possibly score differently on the need for recovery scale. This finding, however, is not able to explain the increased CVD risk in relation to an increased need for recovery, as the relative risk in the model adjusting for psychological distress remained almost unchanged.

No other studies linking a high need for recovery after work with an increased CVD risk have been found in the literature. A concept, which is possibly marginally overlapping, is vital exhaustion. In several studies vital exhaustion has been correlated with an increased CVD risk. ${ }^{14162728}$ Unfortunately, we did not include the concept of "vital exhaustion" in our baseline questionnaire, so a differentiation between vital exhaustion and need for recovery was impossible. However, two important differences can be reported between vital exhaustion and need for recovery. First, we did not find any evidence for a decrease of the CVD risk after one year of follow up, as has been reported for vital exhaustion. ${ }^{14} \mathrm{~A}$ second one is that the questions in the need for recovery questionnaire have a clear link with work, whereas the questions from vital exhaustion are lacking this work related component. Both differences make it more likely that the link between an increased need for recovery and CVD is less likely to be caused by underlying heart disease and is most likely linked to work. However, further study is needed to establish whether the elevated risk can indeed be attributed to an increased need for recovery as a result of adverse working conditions and/or poor coping as indicated by the reported results or is an early sign of impaired functioning of the cardiovascular system, as a sign of underlying cardiovascular disease.

One other study was found which was supportive of the relation between need for recovery and cardiovascular disease risk. This case control study by Sihm and colleagues ${ }^{29}$ showed that "exhaustion after work" was the strongest predictor of an acute myocardial infarction. However, because of the casecontrol design, a strong recall bias cannot be ruled out for this study. Furthermore, Kuiper and colleagues ${ }^{30}$ showed that problems unwinding from work, a concept similar to need for recovery, are related to sympatho-adrenal activation after work. This sympatho-adrenal activation might in turn lead to an increased cardiovascular risk. This finding points towards the physiological mechanism that lies behind the reported results. Further indications for the mechanism we suggest, where need for recovery can be seen as an intermediate factor between job stressors and CVD, can be found in the considerable decrease of the relation between job demands and CVD risk when adjusted for need for recovery.

To summarise, the results of this study showed that need for recovery after work is a predictor of subsequent cardiovascular disease. Further research is needed to evaluate whether this excess risk can be found in other populations. Further investigation is also needed into whether interventions can be devised to reduce the need for recovery, for example, by improving the work environment, and if so, whether these intervention studies are able to reduce the CVD risk.

\section{APPENDIX}

Table Al gives a correlation matrix between need for recovery and other factors.

\section{ACKNOWLEDGEMENTS}

The Maastricht Cohort Study is part of the Netherlands concerted research action on "Fatigue at work" granted by The Netherlands Organisation for Scientific Research (NWO). The work presented in this paper was and is currently supported by The Netherlands Organisation for Scientific Research (NWO grant no. 580-02.201-2).

Authors' affiliations

L G P M van Amelsvoort, IJ Kant, U Bültmann, G M H Swaen,

Department of Epidemiology, Maastricht University, Netherlands

Table A1 Baseline values, correlation matrix

\begin{tabular}{|c|c|c|c|c|c|c|}
\hline & Need for recovery & Sleep quality & $\begin{array}{l}\text { Psychological } \\
\text { distress (GHQ) }\end{array}$ & Job demands & $\begin{array}{l}\text { Decision } \\
\text { latitude }\end{array}$ & Working nights \\
\hline Need for recovery & 1 & -0.33 & 0.47 & 0.35 & -0.13 & 0.05 \\
\hline Sleep quality & -0.33 & 1 & -0.43 & -0.11 & 0.17 & -0.07 \\
\hline Psychological distress (GHQ) & 0.47 & -0.43 & 1 & 0.21 & -0.20 & 0.01 \\
\hline Job demands & 0.35 & -0.11 & 0.21 & 1 & 0.05 & -0.00 \\
\hline Decision latitude & -0.13 & 0.17 & -0.20 & 0.05 & 1 & -0.20 \\
\hline Working nights & 0.05 & -0.07 & 0.01 & -0.00 & -0.20 & 1 \\
\hline
\end{tabular}




\section{REFERENCES}

1 Karasek R, Theorell T. Healthy work. New York: Basic Books, 1990.

2 Siegrist J. Adverse health effects of high effort-low reward conditions. J Occup Health Psychol 1996;1:27-41.

3 Kivimaki $M$, Leino-Arjas $P$, Luukkonen $R$, et al. Work stress and risk of cardiovascular mortality: prospective cohort study of industrial employees. BM 2002;325:857.

4 Bosma $\mathbf{H}$, Marmot MG, Hemingway $\mathrm{H}$, et al. Low job control and risk of coronary heart disease in Whitehall II (prospective cohort) study. BM 1997;314:558-65

5 Steenland K, Johnson J, Nowlin S. A follow-up study of job strain and heart disease among males in the NHANESI population. Am J Ind Med 1997:31:256-60.

6 Theorell T, Tsutsumi A, Hallquist J, et al. Decision latitude, job strain, and myocardial infarction: a study of working men in Stockholm. The SHEEP Study Group. Stockholm Heart Epidemiology Program. Am J Public Health 1998:88:382-8.

7 Kasl SV. The influence of the work environment on cardiovascular health: a historical, conceptual, and methodological perspective. J Occup Health Psychol 1996;1:42-56.

8 Kasl SV. Measuring job stressors and studying the health impact of the work environment: an epidemiologic commentary. J Occup Health Psychol 1998;3:390-401.

9 Kristensen TS. Job stress and cardiovascular disease: a theoretic critical review. J Occup Health Psychol 1996;1:246-60.

10 Belkic K, Savic C, Theorell T, et al. Work stressors and cardiovascular risk: assessment for clinical practice. Part I. Stockholm: Akademitryck, 1995: 1-189.

11 Depue RA, Monroe SM. Conceptualization and measurement of human disorder in life stress research: the problem of chronic disturbance. Psychol Bull 1986;99:36-51.

12 Sluiter JK, van der Beek AJ, Frings Dresen MH. The influence of work characteristics on the need for recovery and experienced health: a study on coach drivers. Ergonomics 1999;42:573-83.

13 Jansen NWH, Kant I, Brandt PA. Need for recovery in the working population: description and associations with fatigue and psychological distress. Int J Behav Med 2002;9:322-40.

14 Appels A, Mulder P. Excess fatigue as a precursor of myocardial infarction. Eur Heart J 1988;9:758-64.

15 Appels A, Otten F. Exhaustion as precursor of cardiac death. Br J Clin Psychol 1992;31(P+ 3):351-6.
16 Appels A, Falger PR, Schouten EG. Vital exhaustion as risk indicator for myocardial infarction in women. J Psychosom Res 1993;37:881-90.

17 Kant IJ, Bultmann U, Schroer CAP, et al. An epidemiological approach to study fatigue in the working population: The Maastricht Cohort Study. Occup Environ Med 2003;60:i32-9.

18 Veldhoven Mv, Meijman T. Het meten van psychosociale arbeidsbelasting [Questionnaire on psychological job demands and job stress]. Amsterdam: NIA-TNO, 1994

19 Sluiter JK, Frings-Dresen MH, van der Beek AJ, et al. The relation between work-induced neuroendocrine reactivity and recovery, subjective need for recovery, and health status. J Psychosom Res 2001;50:29-37.

20 Goldberg DP, Williams P. A user's guide to the Genaral Health Questionnaire. Windsor: NFER-Nelson, 1988

21 Koeter MW, Ormel J. General Health Questionnaire, Handleiding Nederlandse bewerking [General Health Questionnaire, Manual Dutch version]. Lisse, Netherlands: Swets \& Zeitlinger, 1991.

22 Karasek RA. Job Content Questionnaire and user's guide. Los Angeles, CA: Department of Industrial and Systems Engineering, University of Southern California, 1985.

23 APA. Reliability and validity of the Dutch version of the Karasek Job Content Questionnaire. APA/NIOSH conference on work, stress and health, 1995. Washington, DC: APA, 1995.

24 SAS Institute. SAS/STAT user's guide, version 8. Cary, NC: SAS Institute Inc., 1999.

25 Macleod J, Davey Smith G, Heslop P, et al. Psychological stress and cardiovascular disease: empirical demonstration of bias in a prospective observational study of Scottish men. BN 2002;324:1247.

26 Stansfeld SA, Fuhrer R, Shipley M, et al. Psychological distress as a risk factor for coronary heart disease in the Whitehall II Study. Int J Epidemiol 2002;31:248-55.

27 Appels A. Mental precursors of myocardial infarction. Br J Psychiatry 1990;156:465-71.

28 Falger PR, Schouten EG. Exhaustion, psychological stressors in the work environment, and acute myocardial infarction in adult men. J Psychosom Res 1992;36:777-86.

29 Sihm I, Dehlholm G, Hansen ES, et al. The psychosocial work environment of younger men surviving acute myocardial infarction. Eur Heart J 1991;12:203-9.

30 Kuiper JI, Beek AJvd, Meijman TF. Psychosomatic complaints and unwinding of sympathoadrenal activation after work. Stress Medicine $1998 ; 14: 7-12$ 